\title{
Response: Music, image and the sublime
}

Tom Armstrong, University of Surrey

At the end of 'Passion and striving: The language of emotion and political hierarchy', Susan James discusses Burke's concept of the sublime, tracing its origins in his criticisms of Hobbes, Malebranche, and Hume, who, James informs us, 'made the mistake of supposing that fear is invariably a negative affect'. 1 On the contrary, for Burke the experience of fear can arouse pleasure provided that we experience it at a distance sufficient enough to preclude the possibility of immediate danger. As long as we are able to 'contemplate the possibility of danger rather than danger itself' then the consequent feelings of terror and fear may be accompanied by 'delight - a sort of delicious frisson'. As James points out, the source of the sublime for Burke lies primarily in 'the experience of things 'that are greater than we are'.2 Furthermore, the arts assume a central position in affective matters for Burke because they are able to create the distance necessary to arouse the passion of sublimity; as James asserts, Burke recognizes the existence of the sublime in both the natural and the artificial.

The sublime as formulated by Burke will form the starting point for this essay but, as its title implies, James' paper shows how this passion underpinned Burke's widely held political beliefs and I will be outlining ways in which one particular musical genre, music for film, can convey ideological positions later on. Burke, as James points out, implies that the 'power and magnificence' displayed by rulers harnesses the sublime to act as a limit to the ambitions of their subjects; the sublime 'frisson' arising from encounters with such spectacle 'yields a sense of satisfied ambition'.3 This essay will show how the affective techniques of some film music can be linked to Burke's concept of the sublime and how this music can likewise be made to serve ideological ends.

Music for film offers particularly rich ground for the exploration of a musical language of the emotions, leaving considerably less room for semantic ambiguity than its more autonomous manifestations consumed in recorded, broadcast, or live form. In the eighteenth century this ambiguity was sensed most keenly with respect to instrumental music in which the lack of a text was felt to impose serious limits on the music's affective potential. Describing the nature of poetry, music, and their combination, James Harris writes: 'And music, when alone, can only raise affections, which soon languish and decay, if not maintained and fed by the nutritive images of poetry. Yet must it be remembered, in this union, that poetry ever has the precedence; its utility as well as dignity being by far the more considerable'. 4

As Neal Zaslaw points out, such bias was reflected in concert programming where symphonies routinely provided overtures to the main solo items (arias, concertos, keyboard improvisations, etc.) and were rarely considered the focus of a programme. 5 It was only with the later symphonies of Haydn and Mozart from the mid 1780s (particularly the great success of Haydn's 'London' symphonies of the early 1790s) that a shift in attitude on the part of audiences and thinkers became apparent:

'In the contemplation of that immense variety of agreeable and melodious sounds, arranged and digested, both in their coincidence and their succession, into so complete and regular a system, the mind in reality enjoys not only a very great sensual, but a very high intellectual, pleasure, not unlike that which it derives from the contemplation of a great system in any other science'.6

Adam Smith's remark ascribes intrinsic emotional qualities to music and, in so doing, rejects the concept of imitation (of the passions or of vocal utterances, cries, gasps, etc, induced by them) that had formed a central component of eighteenth-century musical aesthetics. If music was a language of the emotions it was one that operated according to its own laws and not with reference to external phenomena.7

Such views permeated the nineteenth century too, prompting, as John Neubauer points out, '[a] change from an aesthetics of affects and expression to one of structure'. For Friederich Schlegel, 'instrumental music is a text, not because it follows language but rather because it has a vocabulary and grammar of its own'. In his critical writing for the Allgemeine Musikalische Zeitung E.T.A., Hoffmann made "no attempt to articulate what is untranslatable in music but . . . rather [discussed] musical materials and their uses'.8 . Of course those nineteenth-century composers wedded to a programmatic tradition, such as Berlioz, Liszt, and Strauss, continued to assert more direct links between music and language and this continued into the twentieth century during which Shostakovich, to give but one example, continually betrayed expressive concerns beyond the purely musical in his symphonies and string quartets. For the most part the generation of avant-garde composers who began their careers after the Second World War represented the opposite pole to composers like 
Shostakovich and his romantic forbears, subordinating affective matters, if they acknowledged them at all, to issues of form and structure. For the late Iannis Xenakis analogies between music and language were inappropriate; on the level of 'substructure' music had more in common with 'space and time'.9 In an interview with Paul Griffiths, Brian Ferneyhough, whilst recognizing the importance of external stimuli to this work, is adamant that his pieces proceed according to a purely musical logic: ' . . my music has nothing in common with programme music. There is a tight web of analogical correspondences attached to an extra-musical idea, it's true, but no story line being followed outside the musical action of unfolding and revealing itself'.10

The above overview is necessarily a broad one but it should give some impression of the contested status of music's linguistic potential over the last three centuries. This contestability is not limited to classical music. The proliferation of popular styles since early in the twentieth century, the growth of a mass audience for them and their affiliation to various sub-cultures has not imbued their constituent sounds with any greater meaning making potential or semantic clarity. On the contrary, the discourse attending popular music foregrounds what Lucy Green terms 'delineated meaning', an awareness, conscious or otherwise, of 'the social context that accompanies its [popular music's] production, distribution or reception'. Inherent meanings, those that 'arise from the conventional inter-relationships of musical materials', are played down. Musical delineations may include aspects of the performers' dress, their way of moving, the value systems belonging to the musicians' or fans' sub-cultures, memories evoked via a repeated hearing, and so forth. This fetishization of delineations imbues popular music's inherent meanings with a sense of the mysterious, as if the delineated meanings are inscribed within rather than by them.11 As a corrective to this, Allan Moore seeks to account for 'the sounds themselves', arguing that 'until we cognize the sounds . . . we have no musical entity to care about, or to which to give value'. Moore does not deny meaning for popular music or that this meaning is located in an amalgam of music and lyrics. However he is sceptical about the fixity of such meanings and the directness of their communication from performer to listener. Instead, lyrics and their accompanying musical sounds become 'grounds for negotiation' as the listener engages in a process of identification with the performer, construing meanings quite freely as they seek to construct their own idea of the performer's persona.12 Green echoes this sense of fluidity, claiming that delineated meanings can be 'both conventional and individual'.13

This strongly individual focus for pop music's delineations is often used powerfully in commercial cinema. In a discussion of the identification process between filmgoer and film, Anahid Kassabian distinguishes between assimilating and affiliating identifications. The former, associated with especially composed scores, help position the viewer within a filmic world, which may bear little relation to their own experience. The latter, associated with compiled scores (which invariably take the form of pop song compilations), encourage viewers to use the associations between the songs and their own personal histories to widen the 'psychic field' within which they identify with the film.14 It is, however, with especially composed scores that the rest of this essay will be occupied.15 I should like to take two examples, from Stanley Kubrick's 2001: A Space Odyssey (1968) and Stephen Speilberg's E.T. (1982), in order to suggest the consistency with which musical idioms and 'image/affect amalgams' are often aligned.16 Such consistency helps lend some credence to the view of film music as an emotional language. What will also become apparent from these examples is how, in relation to certain emotional states, film music approaches Burke's description of the musical sublime.

From the cinema's inception at the end of the nineteenth century, music has been a near constant presence. The demand for suitable music increased with the cinema's growing popularity in the first decade of the twentieth century but it took some time for the concept of an especially composed score to emerge. Musical accompaniment in the early cinema tended to rely on improvised or compiled scores and sometimes a mixture of both. Performing forces ranged from the solo pianist or organist to pit bands or even orchestras, whilst the choice of music and its placement in the film remained largely in the hands of each venue's musical director. One of the early stages in the development of a distinct film scoring practice occurred in 1912 when Max Winkler approached Universal with the idea of producing cue sheets based on their forthcoming releases. These provided musical directors with a list of the precise timings for each musical cue and suggestions for suitable pieces to use, all of which were available from the Carl Fischer music store in New York, Winkler's employer! In Germany, Giuseppe Becce's Kinobibliothek (published in 1919) provided carefully catalogued cues, many by Becce himself, covering an impressive range of emotional states. For example, under the heading 'Dramatic Expression' Becce supplies a variety of dramatic/narrative subheadings including 'Climax', 'TensionMisterioso', 'Tension-Agitato', and 'Climax-Appassionato'; the final heading is further broken down into 'Despair; Passionate lament; Passionate excitement; Jubilant; Victorious; Bacchantic'.

The taxonomic approach adopted by Winkler and Becce has continued to inform the composition and deployment of music in the bulk of commercial cinema releases. Thus, film music has a strongly connotative function helping, together with camera positioning, editing, lighting, and acting to establish, as Claudia 
Gorbman puts it, 'moods and tonalities in a film' and to guide the spectator's vision. 17 Above all, film music functions not in isolation but in combination with a film's visual and sound elements. The musical examples I have chosen, from 2001 and E.T., both employ compositional techniques associated with the European avantgarde.18 These are brought to bear on narrative moments involving notions of 'otherness', the unknown and unboundedness. In both cases the music aims to unsettle the viewer, contributing to a mood of suspense and the attendant emotions of apprehension and fear.

In 2001 a group of astronauts slowly approach the mysterious, jet-black obelisk. They are accompanied by atonal, highly dissonant music, which begins with male voices and gradually expands in register to encompass the full range of a large mixed choir. As the astronauts get nearer to their goal sustained brass notes occasionally cut through the dense choral texture. The climax of the cue occurs as one member of the party reaches out to touch the obelisk. The music coalesces around a high soprano line before quickly subsiding and building again whereupon it is overlaid with a piercing electronic wail which we understand comes from the obelisk itself. As the disorientated astronauts stumble about there is an abrupt cut to the next scene with the wail and the fading music providing the necessary continuity. In E.T. the child-hero of the piece, Elliot, is on guard next to the garden shed. He knows there is something there because he has already stumbled across the creature in the cornfield next to his house. It is night and an establishing shot of the scene is accompanied by a ten-note, atonal melody played twice by the harp, the only melodic material in this sparsely scored cue. As Elliot, who has fallen asleep, opens his eyes and the camera pans right we see E.T.'s diminutive silhouette accompanied by violins performing slow, upward glissandi in their highest register.19 Elliot, who at this point in the film has no idea of the benign nature or extraterrestrial origin of this intruder, tries to call for help but fear produces nothing more than a dry croak. E.T. begins to shuffle out of the shed and the music settles onto a dissonant wind and string chord enlivened by a series of crescendi, which also serve to crank up the level of suspense. The last of these, underpinned by muted brass, forms the climax to the cue as E.T. reaches out a withered hand to deposit in Elliot's lap - a handful of harmless sweets. The sustained chord subsides to be replaced by the celesta, still sinister but less threatening and with a hint of the magical, playing the ten-note melody.

The musical similarities between the above cues are striking, as are those between the mood and tone of the scenes and the emotions suggested to us by the amalgamation of music, image, and narrative. Both cues are atonal, involving a high degree of dissonance, and both eschew a clear sense of rhythmic pulse and meter. Both scenes explore feelings of unease and fear associated with the alien and mysterious. This brief snapshot of film scoring practice points up the degree of consistency with which given musical styles are targeted at certain image/narrative combinations, providing a specific affective colouring and eliciting a corresponding emotional response.

Striking too are the parallels between these cues and Burke's description of the sublime in sound. Sudden and intermittent sounds can both give rise to the sublime, for example a single drum stroke with pauses gives rise to perceptions of danger whilst 'low, confused, uncertain sounds' cause anxiety by means of their concealed sources. Such sounds are parallelled in the cues discussed by the avoidance of both pulse and obvious rhythmic patterning. Neither cue provides us with an audible rhythmic framework within which we can place sounds; without this we are unable to anticipate how the music may develop, we are at the mercy of its unfolding. Although Burke does not provide any sonic examples, the sublime quality of obscurity also finds its equivalent in the musical examples just given, specifically in the Ligeti extract used in 2001. Ligeti's technique of micropolyphony, the weaving together of a mass of melodic strands until the musical texture is saturated, obscures the identity of the individual strands resulting in a dense, shifting sound mass. Indeed, solidity and massiveness constitute two further qualities of the sublime. 20

The presence of sublime elements in the music of Ligeti and Williams seems clear enough, but what of distance, without the security of which our experience of such emotions as apprehension or fear may become uncomfortably immediate? On one level the answer to this seems obvious, the images we see in any film are merely representations of reality and we view these from the comfort of a plush cinema seat or our own living room so naturally we are at several removes from the physical world as represented in the film. But this ignores the fact that one of film music's functions is to attempt to erase the distance between filmgoer and film. For Claudia Gorbman film music in narrative cinema is designed to 'remove our defences against the fantasy structures to which narrative provides access', it makes us more pliant, like muzak, and, by masking the technological aspects of the cinematic medium, it aids our passage into the film's world, imparting to us a sense of ownership of the story.21 Composers of music for the commercial cinema are adept at drawing the viewer into the narrative and making them believe in the reality of the images they see, but underpinning this success is a paradox, one that is articulated with great clarity by Royal Brown. For Brown, the strong dose of affect supplied by most film music has a tendency to mythify the 'cinematic object-event' by which he means that the 
viewer experiences certain moments in the film paradigmatically, transcending time and space as constructed by the narrative. 22 So, at the same time as helping to historicize (convince us as to the reality of), the cinematic object-event music dehistoricizes that event by encouraging a mythic reading of it. Whilst an awareness of these mythic events is part and parcel of viewing pleasure they are also, as Brown points out, degenerate because they encourage a single, unified reading; the viewer/listener's emotional responses are channelled down a very narrow path, leaving little or no room for ambiguity. As an example of myth engendered by a powerful music/visual interaction, Brown cites the fear of the irrational which results from our experience of Hitchcock's visual style and Herrmann's score in the Psycho shower scene; this fear is mythic, argues Brown, because it reflects a deep-seated cultural fear. It is possible to detect the same 'cultural' myth underpinning the consistently atonal writing in the examples from 2001 and E.T. cited above. The disparity between the powerfully determined, apparently unambiguous cultural myths which film music helps create and the polyvalent, contingent manner in which we experience reality constitutes one manifestation of distance within the filmgoing experience; another, internal to the film itself, is the distance between what Brown describes, in semiotic terms, as linguistic and mythic levels of signification. The linguistic level is constituted by the cinematic 'language' and the iconic signs it creates; the mythic level is created by the signifier of image and music, the signified being whatever cultural myth the music/image amalgam is designed to invoke. 23

The mythifying tendency of much commercial film music can easily contribute to a sense of passivity in the viewer/listener.24 When the music to a film does not encourage a mythic level of perception it is often in order to foster a more critical, engaged response; in so doing the distance between the film and its audience is reduced and the sublime is no longer evoked. A good example of this is Edmund Miesel's score to Eisenstein's Battleship Potemkin (1925), in particular the justly famous 'Odessa steps' sequence. This five-minute scene illustrates the brutal reprisal visited upon the citizens of Odessa in response to their support for the Potemkin's mutineers during the 1905 revolution. Composer Miesel parallels the implacable descent of the Tsarist troops with a relentless percussive pounding overlaid with grotesque parodies of military brass tattoos and sinewy, chromatic phrases in the strings. Miesel's percussion-dominated score impresses itself on us not only through its sheer volume (Eisenstein reputedly asked for the audience's toleration to be pushed to the limit in this regard) but because of its refusal to grant any affective support to smaller scale narrative events within the scene. After a little less than two minutes have elapsed a woman, realizing her child has been injured, begins to walk up the steps towards the advancing troops in order to appeal for help. She confronts them, her injured child in her arms, only to become yet another victim of the massacre. A short while later another woman appears on the steps with her baby in a pram; she too is shot and the pram begins a sickening descent ending in predictable tragedy as the scene ends. 25 Neither of these episodes elicits any change in the music, which simply continues its percussive barrage; there is no attempt to create suspense during the standoff between the woman with her child and the troops; there is no trace of the elegiac after the young mother is shot.26 The score's implacable, quasiautonomous progress and it's high volume are what negate the mythifying, entertainment-orientated functions which music so often performs when combined with image and narrative in the cinema. Stripped of these functions the music no longer affords us the sublime security of distance; the physical discomfort we feel at the violence of both music and image has greater immediacy and we are forced to confront Eisenstein's images head on; passivity is not really an option.

In the Odessa steps sequence Miesel's score emerges from the background and imposes itself forcefully on our perception. In a silent film like Battleship Potemkin the term background music may appear unsatisfactory but it should be understood to describe the position of the music in relation to the film's narrative rather than to dialogue or sound effects. In the majority of commercial films the narrative is designed to form the main focus of our attention with the music providing affective colour and support; Claudia Gorbman employs the term 'inaudibility' to describe this aspect of traditional film scoring practice.27 In Battleship Potemkin Eisenstein and Meisel, as we have seen, ride roughshod over certain narrative elements.

The background nature of music in much commercial cinema makes it a particularly effective vehicle for the transmission of ideologies. As Anahid Kassabian writes: 'The well established code [utilised in film music] communicates groupings of ideas that are associated with each other in dominant ideologies, and by communicating these groupings on a non-conscious level the code can buttress and reproduce the very ideologies that produced it'.28 Royal Brown argues along similar lines, by maintaining that our' . . desires and proclivities to perceive as real anything in the cinematic experience but the music, which is generally maintained on a totally separate plane, opens the doors to the possibilities of numerous manipulations by and from the culture producing a given film'.29 Kassabian continues, citing the cultural theorist Theo van Leeuwen: ' . . . hearing in an emotional way is crucial to how that music communicates ideologies, because it makes the ideological work seem personal or private and thus removes the messages from the realms of the political, social, or public'.30 The second part of Kassabian's statement is echoed by Claudia Gorbman who views the 
'sensory background' inhabited by much film music as predisposed towards 'affective manipulation' rather than 'rigorous judgement'.31

In their book Composing for the Films (originally published in 1947), Theodor Adorno and Hanns Eisler launch a sustained attack on standard film music practices of the day (little-changed since their inception) and it is the background, 'lulling' nature of the typical film score, the 'bad habits' associated with it (such as over-use of the leitmotif, the tendency to simply 'repeat' what is obvious from the image and an unquestioning reliance on melody and euphony) together with its 'ideological character' that bear the brunt of their criticism.32 In place of the traditional background role for music Adorno and Eisler advocate greater tension between film and score, reflecting what they perceive as the representational and nonrepresentational tendencies of image and music, respectively. Such tension, so the authors claim, helps call attention to the alienated aspects of the cinema, those, such as camera angle and lighting, which betray its industrial origins; laying bare the artificiality of the medium this way limits its potential for ideological manipulation.

Of the alternative approaches and solutions Adorno and Eisler offer, two resonate with the examples discussed above. Firstly there is the device of interruption, the use of a 'developed musical episode', which 'occupies the whole perception'. The viewer's attention is to be directed away from individual characters to the 'situation as a whole' leading him/her 'back from the sphere of privacy to the major social issue'. This would seem to correspond to Meisel's practice in Battleship Potemkin where his music, taking its cue from the rhythm of the troops' marching feet, focuses relentlessly on the brutality of the authorities, avoiding any identification with the fate of individuals. The tension between the music's impersonal barbarism and Eisenstein's finely detailed, expressive facial close-ups is one of the most affecting things about this sequence. Secondly Adorno and Eisler advocate the use of musical resources found in the work of composers such as Schoenberg, Stravinsky, and Bartok during the first three decades of the twentieth century; these include highly dissonant harmony, atonality, additive rhythm, polyphonic textures, and, above all, an objective approach to composition. Adorno and Eisler characterize an objective approach not as cold or indifferent but as one in which 'everything is the result of the concrete requirements of structure, rather than of the tonal system or of any ready-made pattern'. Such an approach, suggest Adorno and Eisler, is a way of abandoning cliche' and 'prefabricated emotionalism' in favour of deliberate choice based on the specific context in which music is to be used. Adorno and Eisler also argue that a modern musical idiom is inherently better suited to film than the oft-used (in the thirties and forties) nineteenth-century romantic one; liberation from conventional tonality means liberation from the temporal constraints that the unfolding of tonal processes places on any piece of music, thus non-tonal music is predisposed towards the construction of the brief, condensed statements often required in film scoring. But Adorno and Eisler do not deny a more conventional function for modern musical resources in film music; they suggest that the complex, dissonant harmony of 'modern' art music is far better suited than overfamiliar nineteenth-century harmony to expressing emotions such as fear or to associations with the 'unfamiliar and unexplored'.33 In the examples from E.T. and 2001 cited earlier atonal music was employed for precisely the ends Adorno and Eisler advocate, but, in both films, its use is circumscribed by them; where Adorno and Eisler suggest that a modern idiom might be used to express 'extreme tenderness', 'ironic detachment', etc., both John Williams and Stanley Kubrick turn to a nineteenth-century tonal idiom whenever less disturbing emotions are involved.34 It is to be regretted perhaps but it appears that atonality has itself become a cliche' that film composers turn to as unthinkingly as any other they may have at their fingertips.

It is a considerable distance to travel, both culturally and historically, from Enlightenment philosophy to modern day film music. This essay has suggested that film music offers a good opportunity to observe and experience music used as an emotional language system and has shown how the lexicon of film music draws on elements of the Burkean sublime. By mythifying moments within the narrative film music creates the requisite distance (between our highly mediated reading of cinema's composite visual/musical signs and the more ambiguous signs of lived reality) necessary for sublime passions to be experienced. The manipulation of the distance between viewer and film has been seen to be crucial in engaging the critical faculties of the former but as the music moves out of the background and disengages itself from the narrative so the viewer is less able to escape into the safety of cultural myth and the immediacy of the image may cause discomfort rather than pleasure. The sublime as manifested in film music is thus as adaptable to political ends as Burke's sublime image of 'royal magnificence' that he describes in relation to Marie Antoinette; the difference between the two lies in the more insidious way that film music tends to perform its ideological work.35

By means of conventions established at a relatively early point in its development film music has achieved a degree of semantic clarity, which allows it to stake a realistic claim to linguistic status. Moreover, much of this language serves to indicate or even induce emotional states. But the notion of film music as a pure language of emotions is misplaced for, in the majority of films, it rarely functions autonomously; the affective colouring it 
provides is often just that, nuance and emphasis serving to round out a carefully constructed representation of reality. This lack of autonomy in most film music can also undermine its linguistic stability, after all, as Claudia Gorbman reminds us, any music applied to a film will do something precisely because we do not separate visual and sound elements whilst watching.36 Picking up this theme Royal Brown recounts how Erich Wolfgang Korngold, having been misled by the title to Kings Row (1945), produced a 'gloriously scintillating' opening title cue to a film about '. . . a fictional town wherein a kind of 1940's Peyton Place unfolds, complete with a sadistic doctor and the possibility of some father-daughter incest. Did Korngold have to rewrite his overture? No. Does the music work for the film anyway? Absolutely'.37

Adorno's and Eisler's encounter with the culture industry as represented by forties Hollywood called forth ideas for a radical renewal of the musical language in which film scores were composed. Whilst a full scale embrace of musical modernism was always unlikely in an industry revolving around mass entertainment there has been some degree of change and diversification in the musical styles employed in mainstream film music composition; popular music in all its many forms has had a significant impact as has the increasing availability and affordability of digital technology, whilst modernist styles are accepted as an important part of the film composer's vocabulary albeit one with a rather restricted range of uses. As a result contemporary filmgoers are exposed, for the most part unconsciously it must be said, to a wider range of musics than ever before. What has changed little, at least as far as mainstream cinema is concerned, are the underlying principles of composing for films, principles which Adorno and Eisler also wanted to see reconsidered. For example, in most commercial cinema the score is as subservient to the narrative, as 'inaudible' as it ever was in the 'golden age' of the thirties and forties. Increasingly, producers of big budget films appear to be adopting an attitude that the more music a film contains the better; the result of this is that the music tends to vanish even further into the film as the viewer experiences little change in the density of the soundtrack. Given that the less we perceive of the music the more able it is to work ideologically this situation appears far from healthy. Music in the cinema may offer a sublime experience but, in the current international political climate, we would do well to be on guard against the uses to which that experience can be put.

\section{Notes}

1 Susan James, 'Passion and Striving', reprinted in this volume, pp. 55-70.

2 James, 'Passion and Striving'.

3 James, 'Passion and Striving'.

4 James Harris, 1744, in Edward Lippman, A History of Western Musical

Aesthetics (University of Nebraska Press, 1992), p. 100.

5 Neal Zaslaw, Mozart's Symphonies: Context, Performance Practice, Reception (Oxford: Clarendon, 1989).

6 Adam Smith, 1795, in Lippman, History of Western Musical Aesthetics, p. 115.

7 Leonard Ratner's work on rhetoric in eighteenth-century music has shown how, for composers at least, principles and materials extrinsic to music continued to inform compositional practices right through the baroque and classical periods. See Leonard Ratner, Classic Music: Expression, Form and Style (New York: Schirmer, 1980).

8 John Neubauer, The Emancipation of Music from Language (New Haven and London: Yale University Press, 1986), pp. 194, 202, 205.

9 N. Matossian, Xenakis (London: Kahn and Averill, 1990), p. 61.

10 Paul Griffiths, New Sounds, New Personalities: British Composers of the 1980s (London: Faber and Faber, 1985), p. 79.

11 Lucy Green, Music, Gender, Education (Cambridge: Cambridge University Press, 1997), 7, 9.

12 Allan Moore, Rock the Primary Text (Aldershot: Ashgate, 2001), pp. 17, 187.

13 Lucy Green, in Moore, Rock the Primary Text, 1996, p. 197.

14 Anahid Kassabian, Hearing Film: Tracking Identifications in Contemporary Hollywood Film Music (New York and London: Routledge, 2001), pp. 2-3. 
15 The score to Kubrick's 2001 (1968) is in fact a compilation score although, originally, the film was to have been scored by Alex North whose score was rejected. The scene in question uses music from Ligeti's Requiem (1963-5), the modernist idiom of which would not have been at all well known to most cinemagoers and therefore not conducive to affiliating identifications. Because of this the music functions as if it had been specially composed, indeed its dense textures and dissonant harmonic clusters, alongside those of Penderecki's Threnody (1961), have now become part of the film music lexicon, witness John Williams' score for Close Encounters of the Third Kind (1977) and Marco Beltrami's for Scream (1996).

16 Royal Brown, Overtones and Undertones: Reading Film Music (Berkeley, Los Angeles, London: University of California Press, 1994,), pp. 30-1.

17 Claudia Gorbman, Unheard Melodies: Narrative Film Music (Indiana: Indiana University Press, 1987).

18 Two distinct moments within the European avant-garde movement provide the musical materials for these cues. Ligeti's Requiem represents a strain of post-war avant-garde music in which emphasis was placed on textures of massed sounds. Here, surface details of the music were subordinated to the shifting densities and timbral qualities of the overall texture. John Williams' atonal lines on the other hand would not be out of place in a work such as Schoenberg's Pierrot Lunaire of 1912, one of a rush of expressionist pieces through which Schoenberg began to address the challenges of composing without the support of the major/minor tonal system.

19 A common technique in avant-garde string writing, glissandi (slides) are particularly effective on unfretted stringed instruments, which enable the performance of infinite pitch gradations.

20 Edmund Burke, A Philosophical Enquiry into the Origin of our Ideas of the Sublime and the Beautiful, ed. James T. Boulton (Oxford: Blackwell, 1757/ 1987), Part 2: XVIII, XIX, III, XXVII.

21 Gorbman, Vnheard Melodies.

22 This term refers to the way in which the cinema iconifies image and time: we read visual and temporal cinematic signs as real and non-arbitrary. See Brown, op. cit., p. 16 for a full explanation of this.

23 Brown, Overtones and Undertones, p. 31.

24 Brown, Overtones and Undertones, p. 31.

25 Brian de Palma pays homage to this episode in The Untouchables (1987). Ennio Morricone's scoring bears little comparison with Miesel. Morricone also takes a 'single affect' approach to the scene but he is concerned to create a mood of suspense, undercutting the narrative's disturbing violence. Although Morricone's scoring is quite original and undeniably effective, de Palma's use of the, by now rather tired, device of slow motion still encourages a mythic reading of the scene and a degree of passivity we do not experience in Eisenstein.

26 This separation of musical and filmic (visual/narrative) elements looks forward to the 'vertical montage' of Eisenstein's later work in which the image and music tracks are allowed to unfold with a degree of independence whilst still combining to powerful effect.

27 Gorbman, Unheard Melodies.

28 Kassabian, Hearing Film, p. 29.

29 Brown, Overtones and Undertones, p. 17.

30 Kassabian, Hearing Film, p. 29.

31 Gorbman, Unheard Melodies.

32 Adapted from Wagnerian practice, letimotivic technique in film music involves the association of brief musical ideas with key elements of the narrative such as characters, objects and places. E.T. has a plethora of leitmotifs representing the creature itself, its powers and the sinister 'searchers' who seem to be hunting it to name but a few. Leitmotifs frequently undergo transformation in conjunction with elements to which they refer.

33 Theodor Adorno and Hanns Eisler, Composing for the Films (London: Athlone Press, first published NY: Oxford University Press, 1947), pp. 11, 33, 39, 37.

34 It is not easy to think of atonal film scores which are used in connection with anything other than the frightening, the disturbing, the alien, the irrational, and so on; there are however isolated scenes which come to mind. In his outstanding score to Planet of the Apes (1968) Jerry Goldsmith manages to respond to the 
intimacy between Taylor (Charlton Heston) and Nova (Linda Hamilton) without lapsing into tonal cliche's and Bernard Hermann in his score to Psycho (1960), often highly dissonant but rarely atonal, maintains considerable harmonic tension in his underscoring of Marion's and Sam's hotel room liaison at the opening of the film.

35 James, 'Passion and Striving'.

36 Gorbman, Unheard Melodies.

37 Brown, Overtones and Undertones, p. 26. 